\title{
DESAIN SISTEM KENDALI UMPAN BALIK STATE PADA KASUS KONTINYU UNTUK MEJA KERJA CNC
}

\author{
Fakhruddin Mangkusasmito $^{[1]}$, Tsani Hendro Nugroho ${ }^{[2]}$ \\ ${ }^{[1]}$ Program Studi DIII Teknik Elektro Sekolah Vokasi, Universitas Diponegoro \\ ${ }^{[2]}$ BTMEPPO-Badan Pengkajian dan Penerapan Teknologi
}

\begin{abstract}
Fakhruddin Mangkusasmito, Tsani Hendro Nugroho in this paper explain that One of the important control system in the manufacturing industry is the position control. Mainly in the Computer Numerical Control $(C N C)$ machine, work-table motion control system is used to regulate work-table movements when the machine process a workpieces on it. On standard machines, work-table movements are two axes $(X-Y)$, which is driven by a motor and lead-screw. The discussion in this research only focus on one axis assuming that the systems on both axes are the same and independent. In this research, MATLAB is used to describe the behaviour of the system and also to design appropriate control system in continuos system using state feedback linear controller such as pole placement, tracking system, full order compensator and reduced order compensator. The goal is to obtain a fast response with a rapid rise time and settling time to a step command, while not exceeding an overshoot of 5\%. The specification are than a percent overshoot equal to $\%, 0,05$ s settling time and 0,03s rise time. The performance of each control methods are simulated and analyzed to decide the best suit control method for the systems with such criteria. And the result verify that using tracking system controller method achieve such specification with $0 \%$ overshoot, 0,04 s settling time and 0,028 s rise time.
\end{abstract}

Keywords: Computer Numerical Control (CNC), work-table motion control, state feedback control, contionous, MATLAB

\section{PENDAHULUAN \\ Latar Belakang \\ Computer Numerical Control (CNC) adalah} sebuah mekanisme kontol otomatis (drill, alat-alat bor, mesin bubut) yang digunakan pada industri manufaktur modern untuk memproses material bahan (logam, plastik, kayu, keramik, atau komposit) agar memenuhi spesifikasi yang dibutuhkan tanpa menggunakan operator manual. Dengan mesin CNC, ketelitian suatu produk dapat dijamin hingga $1 / 100 \mathrm{~mm}$ lebih, pengerjaan produk massal dengan hasil yang sama persis dan waktu permesinan yang cepat. NC/CNC secara umum terdiri dari enam bagian utama: (1) program, (2) unit kendali atau processor, (3) motor listrik servo untuk menggerakan kontrol pahat, (4) motor listrik untuk menggerakan/memutar pahat, (5) pahat, dan (6) dudukan dan pemegang. Salah satu fungsi dasar dari sebuah mesin CNC adalah kontrol pergerakan yang bersifat otomatis, presisi dan konsisten. Semua bentuk peralatan $\mathrm{CNC}$ memilikki dua tau lebih arah gerakan atau yang disebut sumbu aksis (axes). Aksisaksis ini dapat diperasikan secara presisi dan otomatis di sepanjang jalur pergerakannya. Dua sumbu aksis yang paling umum digunakan adalah tipe linier (bergerak sepanjang jalur lurus) dan rotary (bergeak sepanjang jalur melingkar). Mesin $\mathrm{CNC}$ menerima perintah mengenai posisi work-table yang diinginkan dari program CNC. Motor servo penggerak berputar dalam jumlah yang dibutuhkan, yang pada gilirannya akan memutar ballscrew, dan mengakibatkan pergerakan linier aksis. Perangkat umpan balik (sensor) akan mengkonfirmasi jumlah putaran yang tepat dari ballscrew tersebut. Gambar 1 menunjukan motion control dari work-table CNC.

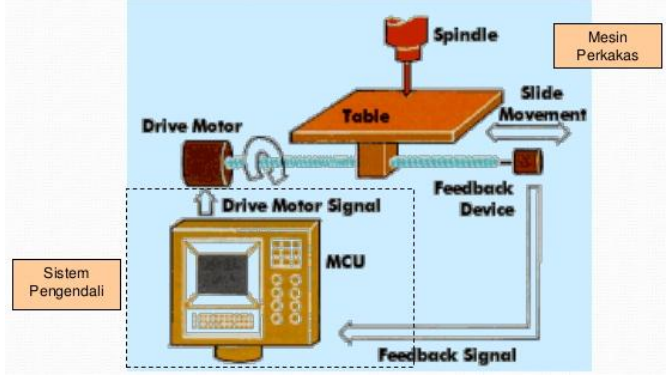

Gambar 1. Motion control dari work-table CNC

Di sisi lain state feedback controller, termasuk di dalamnya metode pole placement, estimator berorde penuh dan estimator berorde tereduksi secara umum merupakan metode kontrol yang menggunakan umpan balik dari sistem untuk menempatkan kutub-kutub dari sistem ke lokasi yang diinginkan pada bidang-s. Penempatan kutub-kutub sistem ini sangat diharapkan karena berhubungan secara langsung dengan nilai eigen sistem, yang mana berpengaruh pada karakteristik respon sistem. Implementasi metode state feedback controller juga relatif mudah dibandingkan dengan controller lain yang juga digunakan di mesin CNC seperti fuzzy [1], robust control [2] dan fuzzy-PID [3]. Salah satu controller yang umum digunakan dalam aplikasi industri adalah metode PID karena implementasinya yang juga mudah ${ }^{[8]}$. Karakter performansi sistem kontrol sering dinyatakan dalam bentuk respon 
transien terhadap masukan tangga satuan (step) karena mudah dibangkitkan dan cukup radikal (bila respon terhadap masukan step diketahui, maka secara matematis dapat dihitung respon terhadap setiap masukan). Respon transien suatu sistem terhadap masukan step bergantung pada syarat awal. Untuk memudahkan perbandingan respon transien berbagai sistem, hal yang biasa dilakukan adalah menggunakan syarat awal standar bahwa sistem mula-mula dalam keadaan diam sehingga keluaran dan semua turunan waktunya pada awal respon sama dengan nol, selanjutnya karakteristik respon secara mudah dapat dibandingkan. Spesifikasi kawasan waktu yang dijelaskan ini cukup penting, karena sebagian besar sistem kontrol adalah sistem kawasan waktu, yang berarti sistem ini harus menunjukkan respon waktu yang dapat diterima, atau sistem kontrol harus dimodifikasi sampai respon transiennya memuaskan [6]. Tujuan penelitian ini adalah menganalisis penggunaan metode state feedback controller untuk mengontrol mekanisme work-table agar memenuhi spesifikasi umum industri yang diinginkan.

\section{Batasan Masalah}

Dalam penelitian ini ada beberapa batasan masalah yang digunakan, yaitu model matematik yang digunakan menggunakan model work-table pada ${ }^{[3]}$. Analisis yang dilakukan pada penelitian ini menggunakan hasil simulasi yang dibangun pada software MATLAB. Target penelitian ini adalah mendesain sistem kendali posisi yang memiliki respon yang cepat dengan rise time (Tr) dan settling time (Ts) yang pendek untuk input step serta mempunyai overshoot kurang dari $1 \%$ Untuk memenuhi target penelitian dan mendapatkan respon sistem work-table yang baik, spesifikasi sistem yang ditetapkan pada penelitian ini ialah

- Overshoot maksimal : $1 \%$

- $\quad$ Settling time : 0,05s

- $\quad$ Rise time : $0,03 \mathrm{~s}$

SISTEM WORKTABLE MOTION CONTROL SYSTEM MESIN CNC

Blok Diagram Worktable Motion Control System Mesin CNC

Blok diagram sistem worktable motion control system yang digunakan dalam penelitian ini dapat dilihat pada Gambar 2. [3]

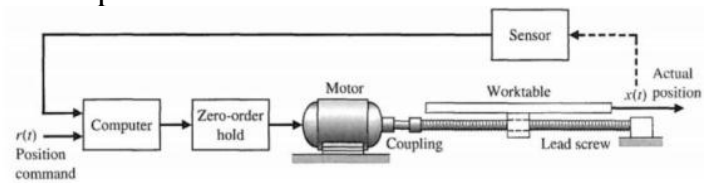

Gambar 2. Blok diagram work-table mesin CNC

Pada penggerak $\mathrm{x}$-axis, meja-kerja dipasang pada sebuah lead-screw yang di couple ke sistem motor. Lead-screw difungsikan untuk mengkonversi sistem gerak rotasi motor ke sistem gerak translasi untuk memposisikan mejakerja pada koordinat $\mathrm{x}$ yang diinginkan. Sistem motor terdiri dari motor dan power amplifier dengan algoritma kendali yang akan diimplementasikan pada sebuah embedded komputer atau PC. Untuk feedback digunakan sensor jenis distance-meter (tipe infrared atau laser) untuk mengukur posisi $\mathrm{x}$ meja-kerja dari homeposition-nya.

\section{Representasi Model Kontinyu}

Untuk mendesain sistem kontrol dalam kawasan kontinyu, maka digunakan fungsi alih yang terdiri dari fungsi alih motor dan fungsi alih power amplifier ${ }^{[3]}$. Fungsi alih total dari sistem tersebut ialah

$$
G p(s)=\frac{1}{s(s+10)(s+20)}=\frac{1}{s^{3}+30 s^{2}+200 s}
$$

Dari fungsi alih sistem tersebut, dapat kita analisis respon sistem lup terbuka dan lup tertutup sistem terhadap masukan step dengan menggunakan perintah MATLAB sebagai berikut

$\%$ Plant Gp(s) --> Power Amplifier \& Motor

$\%$ Power Amp Motor

$\% 11$

$\%$

$\%(\mathrm{~s}+20) \mathrm{s}(\mathrm{s}+10)$

numGp $=1$;

$\operatorname{denGp}=\operatorname{poly}([0-10-20])$;

$\%$ Fungsi alih: open-loop

$\mathrm{Gp} \_\mathrm{tf}=\mathrm{tf}($ numGp, denGp)

$\%$ Plot step response: open-loop

step(Gp_tf)

hold on

$\%$ Fungsi alih: close-loop (feedback gain $=1$ )

Gp_tfcl $=$ feedback $\left(G p \_t f, 1\right)$

5

$\%$ Plot step response: close-loop

step(Gp_tfcl)

legend('Open-loop', 'Close-loop');

hold off

Sehingga didapat respon seperti pada Gambar 3.

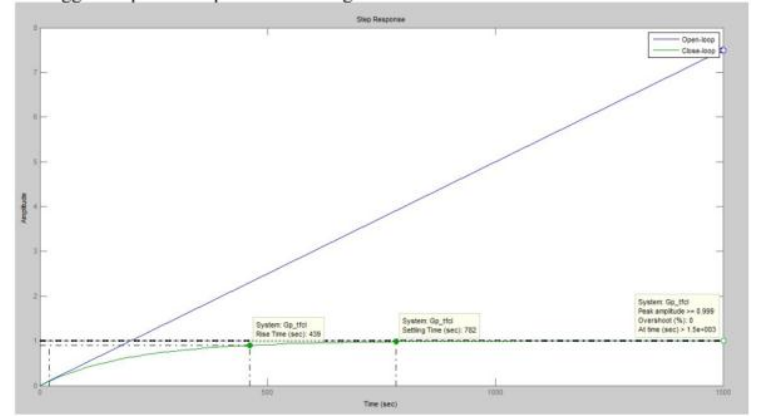

Gambar 3. Respon sistem lup terbuka dan lup tertutup terhadap masukan step

Dari Gambar 3. terlihat bahwa sistem lup terbuka bersifat tidak stabil dan sistem lup tertutup bersifat stabil sesuai dengan krieria kestabilan sistem kontrol [6] [9]. Dengan spesifikasi sistem lup tertutup sebagai berikut: 
- Overshoot maksimal : 0\%

- $\quad$ Settling time : 782s

- $\quad$ Rise time : 432s

Dari hasil simulasi pada sistem lup tertutup terlihat bahwa nilai overshoot sistem sudah memenuhi spesifikasi sistem, sedangkan nilai settling time sangat jauh dari spesifikasi (dari target $0.05 \mathrm{~ms}$ ) sehingga diperlukan desain kendali untuk memperbaiki nilai settling time dan rise time tersebut agar sesuai spesifikasi yang diharapkan.

Selanjutnya, untuk mengimplementasikan sistem kendali state feedback controller fungsi alih total sistem perlu diubah ke bentuk state space kontinyu, transformasi tersebut dilakukan ddengan perintah MATLAB berikut:

$\%$ Representasi state space

$[\mathrm{F}, \mathrm{G}, \mathrm{H}, \mathrm{J}]=\mathrm{tf} 2 \mathrm{ss}($ numGp, $\operatorname{denGp})$;

Gp_ss $=$ ss $(\mathrm{F}, \mathrm{G}, \mathrm{H}, \mathrm{J})$

Dari hasil transformasi MATLAB maka diperoleh hasil sebagai berikut

\begin{tabular}{|c|c|c|}
\hline & -30 & 200 \\
\hline Matriks $F=$ & 1 & 0 \\
\hline 1 & 0 & 1 \\
\hline Matrik $G=0$ & & \\
\hline $\begin{array}{l}\text { Matrik } H=0 \\
\text { Matrik } J=0\end{array}$ & 0 & 1 \\
\hline
\end{tabular}

Dari hasil hasil tersebut maka dapat disusun menjadi bentuk umum persamaan state space sebagai berikut

$$
\begin{aligned}
& {\left[\begin{array}{l}
\dot{x} 1 \\
\dot{x} 2 \\
\dot{x} 3
\end{array}\right]=\left[\begin{array}{ccc}
-30 & -200 & 0 \\
1 & 0 & 0 \\
0 & 1 & 0
\end{array}\right]\left[\begin{array}{l}
x 1 \\
x 2 \\
x 3
\end{array}\right]+\left[\begin{array}{l}
1 \\
0 \\
0
\end{array}\right] u} \\
& y=\left[\begin{array}{lll}
0 & 0 & 1
\end{array}\right]\left[\begin{array}{l}
x 1 \\
x 2 \\
x 3
\end{array}\right]
\end{aligned}
$$

Selanjutnya untuk mengecek kestabilan sistem dapat dilakukan dengan melihat tempat kedudukan akar (root locus) dari [4], [6]. Pengecekan tempat kedudukan akar dari sistem dapat dilakukan dengan perintah MATLAB berikut

$\%$ root locus open-loop rlocus(Gp_ss)

Hasil tempat kedudukan akar dari sistem kontinyu tersebut dapat dilihat pada Gambar 4.

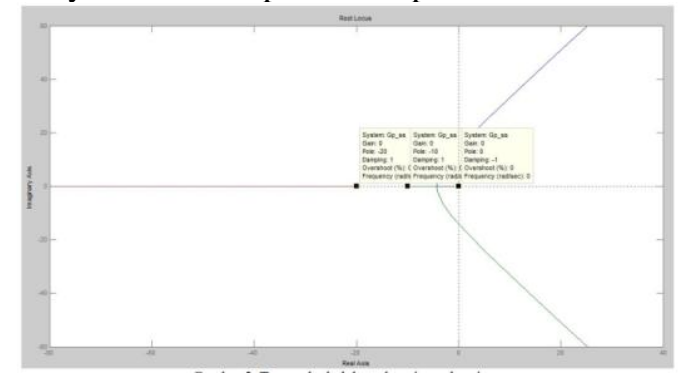

Gambar 4. Tempat kedudukan akar sistem kontinyu
Dari Gambar 4. terlihat bahwa sistem termasuk dalam kriteria stabil karena kutub-kutub sistem terletak di sebelah kiri sumbu imajiner.

Selanjutnya dari persamaan state space tersebut dapat dibangun menggunakan Simulink seperti pada Gambar 5.

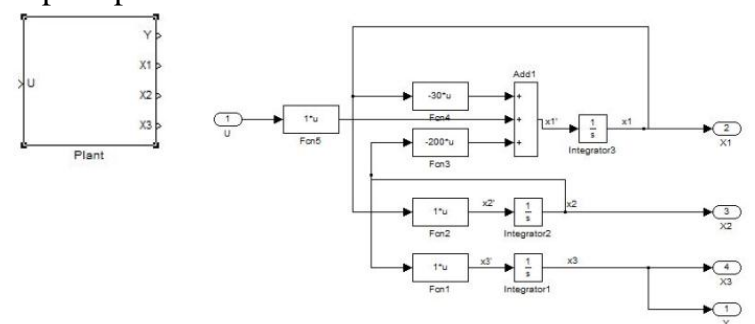

Gambar 5. Plant simulink work-table mesin CNC

\section{Keterkendalian (Controllability) dan Keteramatan (Observability) Sistem}

Setelah mendapatkan representasi sistem dalam bentuk state space, kita perlu mengecek kondisi keterkendalian (controllability) dan keteramatan (observability) sistem, sehingga sistem kontrol yang didesain dapat diimplementasikan pada sistem [11]. Pengecekan tersebut dilakukan menggunakan perintah MATLAB berikut:

$\%$ Controllability

$\%$ Find Controllability matrix

$\mathrm{Gp} \_\mathrm{ctrl}=\left[\mathrm{G} \mathrm{F}^{*} \mathrm{G} \mathrm{F}^{*} \mathrm{~F}^{*} \mathrm{G}\right]$

$\%$ Check controllability

if $\left(\operatorname{rank}\left(\mathrm{Gp} \_\mathrm{ctrl}\right)==\operatorname{size}(\mathrm{F}, 1)\right)$

disp('System is controllable.');

else

disp('System is NOT controllable.');

end

$\%$ Observability

$\%$ Find Observability matrix

Gp_obsv $=\left[\mathrm{H} ; \mathrm{H}^{*} \mathrm{~F} ; \mathrm{H}^{*} \mathrm{~F}^{*} \mathrm{~F}\right]$

$\%$ Check observability

if $\left(\operatorname{rank}\left(\mathrm{Gp} \_o b s v\right)==\operatorname{size}(\mathrm{F}, 1)\right)$

disp('System is observable.');

else

disp('System is NOT observable.');

Hasil dari perintah MATLAB tersebut diperlihatkan oleh Gambar 6

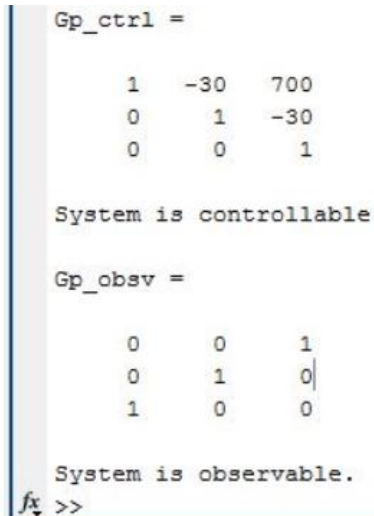

Gambar 6. Pengecekan keterkendalian dan keteramatan sistem 
Dari pengecekan keterkendalian (controllability) dan keteramatan (observability) sistem terlihat bahwa sistem work-table tersebut bersifat terkontrol dan teramati.

\section{CONTROLLER DESIGN}

Konfigurasi umum dari sistem kendali state feedback controller yang akan dibuat pada penelitian ini mengacu pada ${ }^{[4]}$ yang diperlihatkan Gambar 7.

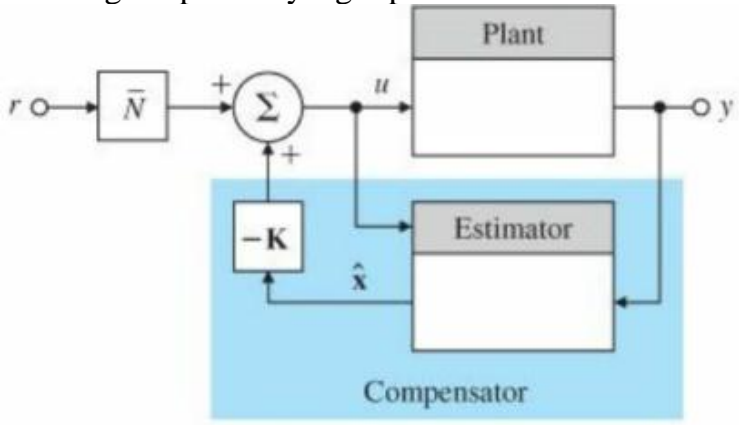

Gambar 7. Konfigurasi state feedback controller

Dari konfigurasi yang diperlihatkan oleh Gambar 7. tersebut maka target desain ini adalah mendapatkan nilai penguatan umpan balik $\mathrm{K}$ dan penguatan input $\mathrm{N}$, serta desain estimator. Pada metode pole placement desain controller hanya akan menentukan nilai $\mathrm{K}$, sedangkan pada metode Tracking system selain nilai $\mathrm{K}$, ditentukan pula nilai $\mathrm{N}$, dan untuk metode estimator berorde penuh dan tereduksi, makan ditentukan pula estimator selain nilai $\mathrm{K}$ dan $\mathrm{N}$. Masing- masing desain controller tersebut akan dianalisis berdasarkan spesifikasi sistem work-table yang telah ditentukan.

\section{Pole Placement}

Pole placement adalah metode yang digunakan dalam teori sistem kontrol umpan balik untuk menempatkan pole baru pada plant lup tertutup yang telah ditentukan di bidang $S{ }^{[11]}$. Untuk meletakkan pole baru suatu sistem maka ditambahkan gain feedback yang ditunjukkan oleh Gambar 8 .

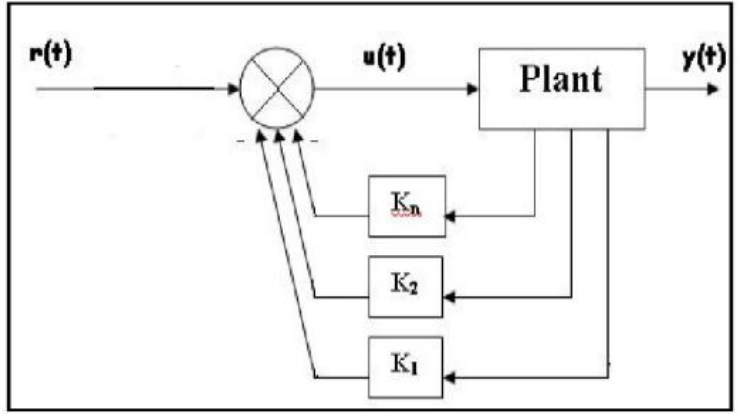

Gambar 8. Skema kendali metode pole placement

Dalam menentukan pole-pole sistem agar karakteristiknya sesuai dengan spesifikasi yang diharapkan digunakan metode pendekatan Second order dominat poles yang ditentukan dengan rumus berikut ${ }^{[6]}$

$$
\begin{aligned}
& s_{1,2}=-\xi \omega_{n} \pm \omega_{n} \sqrt{\xi^{2}-1}, \text { dengan } \\
& \xi=\frac{-\ln (\% O S / 100)}{\sqrt{\pi^{2}+\ln ^{2}(\% O S / 100)}} \\
& \boldsymbol{T}_{s}=\frac{4}{\xi \omega_{n}}
\end{aligned}
$$

Nilai $T_{s}$ dan $\% O S$ ditentukan sesuai dengan spesifikasi yang ditetapkan $(0,05$ s dan $1 \%)$. Sistem work-table ini memilikki orde sistem 3, sehingga letak kutub ke-3 dari sistem diletakkan jauh dari ke-2 kutub dominan dan terletak pada sumbu riil. dengan persamaan

$s_{3}=-10 \times \zeta \omega_{n}$

\section{Tracking System}

Masalah penjejakan (tracking) sistem pada dasarnya adalah membuat output agar dapat menjejak input referensi. Sistem akan mempunyai kesalahan keadaan setimbang tak nol terhadap masukan langkah. Untuk mengoreksinya, pada keadaan setimbang dihitung nilai status dan masukan kendali yang menghasilkan kesalahan keluaran nol, kemudian menekannya untuk bertahan pada nilai ini. Maka dirancang suatu sistem pengendalai yang ditunjukkan oleh Gambar 9. ${ }^{\text {[7] }}$.

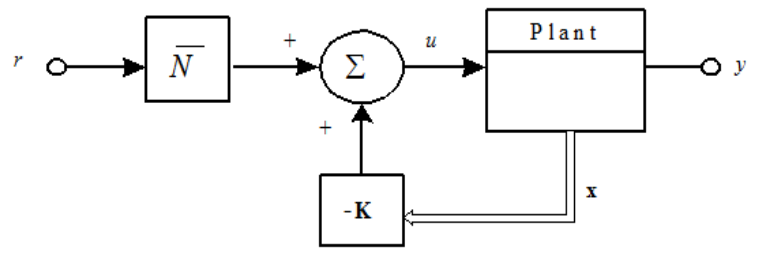

Gambar 9. Skema kendali state feedback dengan tracking system

Agar diperoleh kesalahan setimbang nol, maka sinyal kendali $u$ perlu memenuhi persamaan:

$\mathrm{u}=\mathrm{N}_{\mathrm{u}} \mathrm{r}-K\left(x-N_{x} \mathrm{r}\right)$

$$
=-K x+\left(\mathrm{N}_{\mathrm{u}}+K N_{x}\right) \mathrm{r}
$$

atau

$\mathrm{u}=-K x+\bar{N} r$

dimana konstanta $r$ adalah referensi dan $\bar{N}=N_{u}+K N_{x}$, sedangkan nilai $N_{u}$ dan $N_{x}$ diperoleh dengan menyelesaikan persamaan berikut

$\left[\begin{array}{l}N_{\mathrm{x}} \\ \mathrm{N}_{\mathrm{u}}\end{array}\right]=\left[\begin{array}{ll}F & G \\ H & \mathrm{~J}\end{array}\right]^{-1}\left[\begin{array}{l}0 \\ 1\end{array}\right]$

\section{Estimator Berorde Penuh}

Pada kenyataannya, tidak semua variable state dapat diukur, dikarenakan keterbatasan sensor atau secara fisik tidak dapat diukur, misalnya dalam sistem pembangkit nuklir. Sehingga diperlukan suatu estimator (atau observer) agar dapat memperoleh semua state variable hanya dengan beberapa hasil pengukuran yang ada. Jika estimasi status dinyatakan sebagai $\dot{\hat{x}}$, maka sinyal kendali sistem dengan estimator dinyatakan sebagai $u=-K \hat{x}$, persamaan 
dan skema pengendalian dengan estimator berorder penuh dapat dilihat pada Gambar 10.

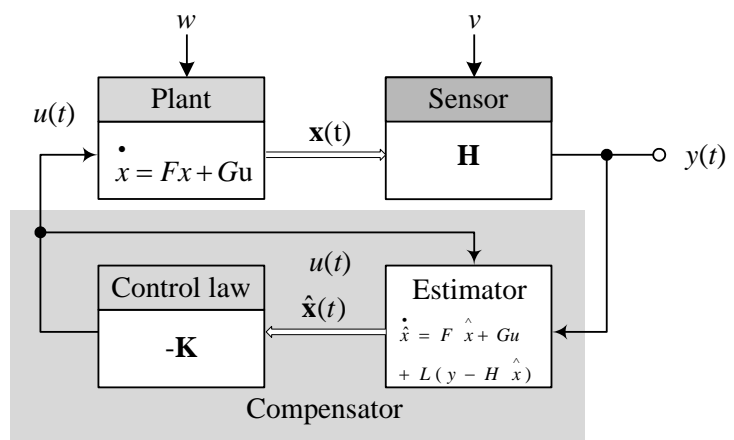

Gambar 10. Skema kendali state feedback dengan estimator berorde penuh

Untuk mendapatkan estimator perlu dicari nilai gain $L$ dengan menempatkan kutub estimator, pada umumnya estimator dirancang agar 5 kali lebih cepat dari dominant poles yang diinginkan ${ }^{[12]}$

\section{Estimator Berorde Tereduksi}

Bentuk lain dari estimator yang dapat dibuat adalah sebuah estimator berorde tereduksi. Desain estimator ini bertujuan untuk menyederhanakan komputasi, sehingga nilai state yang dapat terukur tidak perlu diestimasi. Estimator berorde tereduksi terdiri atas gain umpan balik pengendali dan sebuah estimator berorde tereduksi yang jumlah keluaran estimator, pada penelitian ini akan dikurangi 1 state. Dari representasi state space system yang ada, dibangun estimator berorde tereduksi sebagai berikut:

$$
\begin{aligned}
& {\left[\begin{array}{l}
\dot{x} 1 \\
\dot{x 2} \\
\dot{x} 3
\end{array}\right]=\left[\begin{array}{cc|c}
-30 & -200 & 0 \\
1 & 0 & 0 \\
\hline 0 & 1 & 0
\end{array}\right]\left[\begin{array}{l}
x 1 \\
\frac{x 2}{x 3}
\end{array}\right]+\left[\begin{array}{l}
1 \\
0 \\
0
\end{array}\right] u} \\
& y=\left[\begin{array}{llll}
0 & 0 & 1 & 1
\end{array}\right]\left[\begin{array}{l}
x 1 \\
\frac{x 2}{x 3}
\end{array}\right]
\end{aligned}
$$

state space tersebut dikelompokkan menjadi

$\left[\begin{array}{c}\dot{\mathrm{x}}_{\mathrm{a}} \\ \dot{\mathrm{x}}_{\mathrm{b}}\end{array}\right]=\left[\begin{array}{cc}\mathrm{F}_{\mathrm{aa}} & \mathrm{F}_{\mathrm{ab}} \\ F_{\mathrm{ba}} & F_{\mathrm{bb}}\end{array}\right]\left[\begin{array}{l}\mathrm{x}_{\mathrm{a}} \\ x_{\mathrm{b}}\end{array}\right]+\left[\begin{array}{c}\mathrm{G}_{\mathrm{a}} \\ G_{\mathrm{b}}\end{array}\right] \mathrm{u}=\left[\begin{array}{cc}\mathrm{F}_{\mathrm{aa}} & 0 \\ F_{\mathrm{ba}} & 0\end{array}\right]\left[\begin{array}{l}\mathrm{x}_{\mathrm{a}} \\ x_{\mathrm{b}}\end{array}\right]+\left[\begin{array}{c}\mathrm{G}_{\mathrm{a}} \\ 0\end{array}\right] \mathrm{u}$ $\mathrm{y}=\left[\begin{array}{ll}0 & 1\end{array}\right]\left[\begin{array}{l}\mathrm{x}_{\mathrm{a}} \\ x_{\mathrm{b}}\end{array}\right]$

Dengan dinamika state tak terukur:

$\dot{\mathrm{x}}_{\mathrm{a}}=\mathrm{F}_{\mathrm{aa}} \mathrm{x}_{\mathrm{a}}+F_{\mathrm{ab}} x_{\mathrm{b}}+\mathrm{G}_{\mathrm{a}} \mathrm{u}=\mathrm{F}_{\mathrm{aa}} \mathrm{x}_{\mathrm{a}}+\mathrm{G}_{\mathrm{a}} \mathrm{u}$

nilai $\mathrm{G}_{\mathrm{a}} \mathrm{u}$ diketahui dan dianggap sebagai masukan, dan dinamika state yang terukur ialah

$$
\begin{aligned}
& \dot{\mathrm{x}_{\mathrm{b}}}=F_{\mathrm{ba}} x_{\mathrm{a}}+F_{\mathrm{bb}} x_{\mathrm{b}}+G_{\mathrm{b}} \mathrm{u}=F_{\mathrm{ba}} x_{\mathrm{a}} \\
& y=x_{b} \longrightarrow \dot{y}=\dot{x}_{b} \\
& \text { atau } \\
& \dot{\mathrm{y}}=F_{\mathrm{ba}} x_{\mathrm{a}} \\
& * \quad * * \\
& *=\text { diketahui } \\
& * *=\text { tak diketahui }
\end{aligned}
$$

Dengan melakukan proses subtitusi didapatkan persamaan state space baru sebagai berikut:

$$
\begin{aligned}
& \dot{\hat{x}}=F \hat{x}+G \mathrm{u}+\mathrm{L}(\mathrm{y}-H \hat{x}) \\
& \text { dengan, } \\
& \quad x \leftarrow x_{\mathrm{a}}, \\
& F \leftarrow F_{\mathrm{aa}}, \\
& G \mathrm{u} \leftarrow G_{\mathrm{a}} \mathrm{u}, \quad \longrightarrow \hat{x}_{a}=F_{a} \\
& \mathrm{y} \leftarrow \dot{\mathrm{y}}, \\
& H \leftarrow F_{\text {ba }} .
\end{aligned}
$$

Nilai gain estimator $L$ dicari menggunakan persamaan state baru tersebut dengan perancangan yang sama dengan estimator berorde penuh yaitu agar 5 kali lebih cepat dari dominant poles yang diinginkan. Skema kendali state feedback dengan estimator berorde tereduksi dapat dilihat pada Gambar 11.

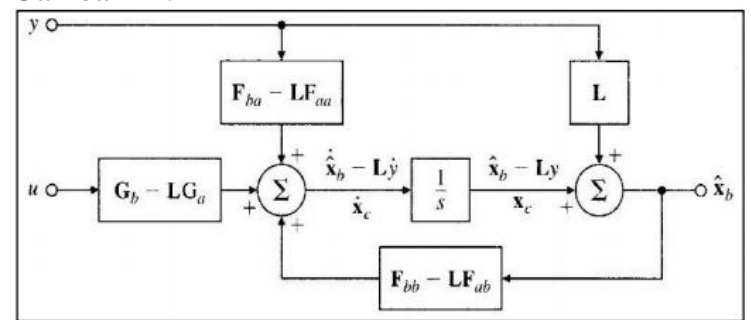

Gambar 11. Skema kendali state feedback dengan estimator berorde tereduksi

\section{PENGUJIAN CONTROLLER}

Simulasi skema kendali state feedback dilakukan berdasarkan desain controller dan spesifikasi kontrol yang diharapkan.

\section{Simulasi Metode Kendali Pole Placement}

Berdasarkan plant sistem pada Gambar 4. dan skema kendali pole placement pada Gambar 8., dibangun sistem pengendalian yang diperlihatkan pada Gambar 12.

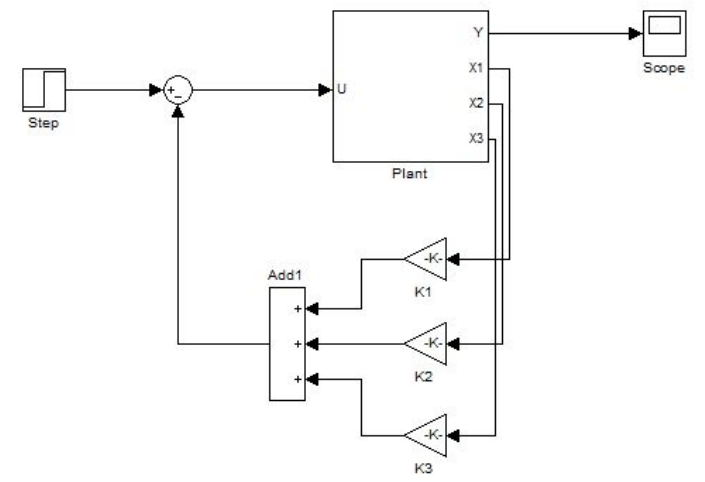

Gambar 12. Skema kendali metode pole placement pada sistem work-table $\mathrm{CNC}$

Untuk mendapatkan respon sistem sesuai spesifikasi sistem serta penentuan gain feedback K, maka digunakan persamaan yang telah dijelaskan sebelumnya tentang desain metode pole placement. 
Persamaan tersebut diselesaikan menggunakan fungsi MATLAB berikut

$\%$ find desired poles from specifications

$\%$ Methode: Dominant poles of second-order system

$\mathrm{PO}=1 \% \%$ Overshoot

$\mathrm{Ts}=0.05 \%$ Settling time

Calculate desired damping ratio (zheta)

$\mathrm{tmp}=\mathrm{pi}^{\wedge} 2+\log (\mathrm{PO} / 100)^{\wedge} 2$

zheta $=-\log (\mathrm{PO} / 100) / \mathrm{sqrt}(\mathrm{tmp})$

$\%$ Calculate desired natural freq

wn $=4 /($ zheta $*$ Ts $)$

$\%$ Desired poles

19

zhetaWn = -zheta*wn;

wd $=$ wn*sqrt $(1-$ zheta*zheta $)$;

dPoles $=[$ zhetaWn+wd*i zhetaWn-wd*i 10*zhetaWn $]$

\%ref: Linear state space

control system

$\%$

$\%$ Full state feedback law...

$\mathrm{K}=$ place $(\mathrm{F}, \mathrm{G}, \mathrm{dPoles})$

Dari spesifikasi yang diinginkan tersebut diperoleh gain feedback K = [900 137200 7502700]. Gain tersebut selanjutnya digunakan sesuai skema pada Gambar 12 , dan didapatkan respon sistem seperti pada Gambar 13.

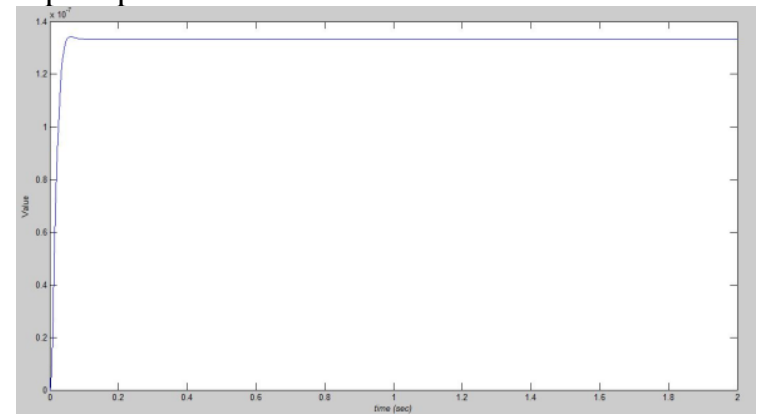

Gambar 13. Respon sistem work-table CNC dengan skema pengontrolan pole placement

Dari hasil simulasi didapatkan:

- Maksimal overshoot (\%OS) : 0,71\%

- $\quad$ Settling Time (Ts) : $0.07 \mathrm{~s}$

- $\quad$ Rise Time (Tr) : $0.023 \mathrm{~s}$

\section{Simulasi Metode Kendali Tracking System}

Berdasarkan plant sistem pada Gambar 4. dan skema kendali tracking system pada Gambar 9, dibangun sistem pengendalian yang diperlihatkan pada Gambar 14.

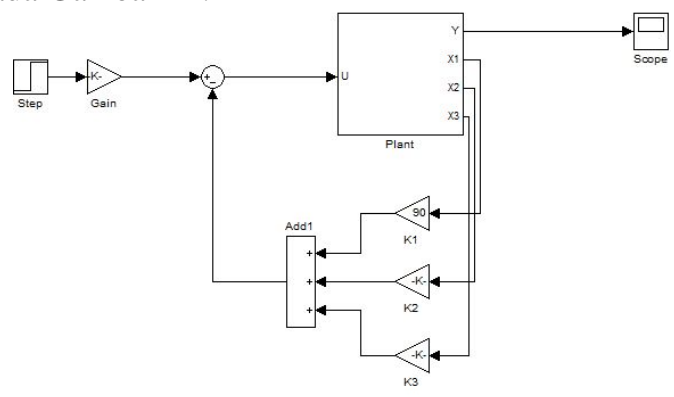

Gambar 14. Skema kendali metode Tracking system pada sistem work-table CNC
Untuk mendapatkan respon sistem sesuai spesifikasi sistem serta gain tracking $\mathrm{N}$, maka digunakan persamaan yang telah dijelaskan sebelumnya tentang desain metode tracking system. Persamaan tersebut diselesaikan menggunakan fungsi MATLAB berikut

$\%$ Menghitung Nbar..

$\mathrm{s}=\operatorname{size}(\mathrm{F}, 1)$;

$\mathrm{Z}=[\operatorname{zeros}([1, \mathrm{~s}]) 1]$;

$\mathrm{N}=\operatorname{inv}([\mathrm{F}, \mathrm{G} ; \mathrm{H}, \mathrm{J}]) * \mathrm{Z}^{\prime}$;

$\mathrm{Nx}=\mathrm{N}(1: \mathrm{s})$;

$\mathrm{Nu}=\mathrm{N}(1+\mathrm{s})$;

$\mathrm{Nbar}=\mathrm{Nu}+\mathrm{K}^{*} \mathrm{Nx}$;

Didapatkan gain tracking $\mathrm{N}=$ [7502700]. Gain tersebut selanjutnya digunakan sesuai skema pada Gambar 14 dan didapatkan respon sistem seperti pada Gambar 15

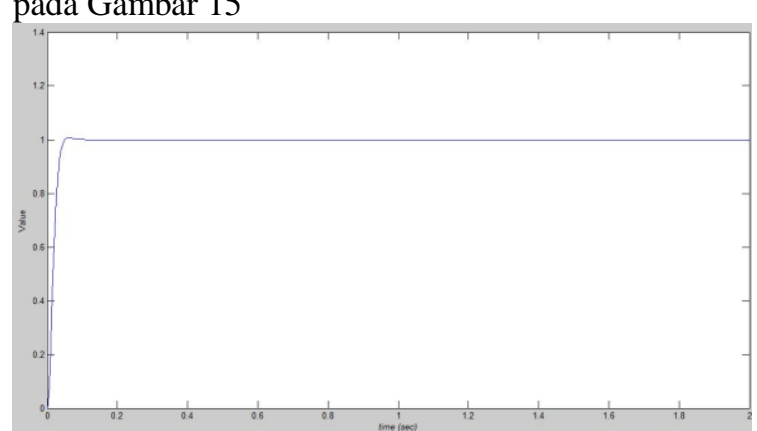

Gambar 15. Respon sistem work-table CNC dengan skema pengontrolan tracking system

Dari hasil simulasi didapatkan:

- Maksimal overshoot (\%OS) : 0\%

- $\quad$ Settling Time (Ts) : 0.04s

- $\quad$ Rise Time (Tr) : $0.028 \mathrm{~s}$

\section{Simulasi Metode Kendali Estimator Berorde Penuh}

Berdasarkan plant sistem pada Gambar 4. dan skema kendali dengan estimator berorde penuh pada Gambar 10., dibangun sistem pengendalian yang diperlihatkan pada Gambar 16.

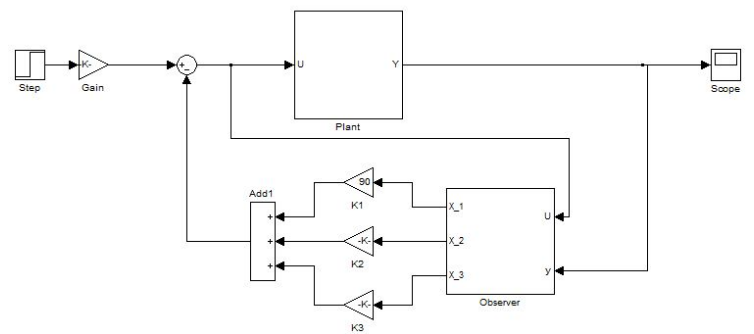

Gambar 16. Skema kendali estimator berorde penuh pada sistem work-table $\mathrm{CNC}$

Model simulink MATLAB untuk estimator berorde penuh diperlihatkan oleh Gambar 17. 


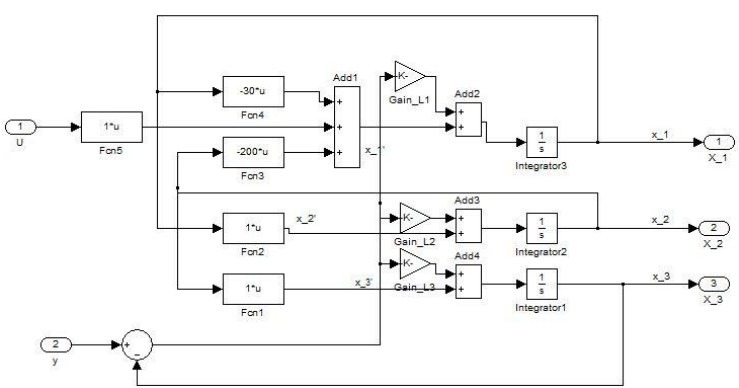

Gambar 17. Skema full order estimator

Pada pengontrolan menggunakan estimator berorde penuh perlu ditentukan gain tracking $\mathrm{N}$, gain feedback K, dan gain feedback L pada estimator, untuk pole pada estimator dipilih agar respon estimator lebih cepat 10 kali dari plant sistem, untuk menetukan gain - gain yang diperlukan digunakan perintah MATLAB sebagai berikut

$\%$ Full state observer

$\%$ from ref: Linear state space control system

$\%$ desired poles of observer --> $5 \mathrm{x}$

dPoles_obsv $=5 *$ dPoles;

$\mathrm{L}=$ place $\left(\mathrm{A}^{\prime}, \mathrm{C}^{\prime}, \mathrm{dPoles} \_ \text {obsv }\right)^{\prime}$

Didapatkan nilai gain feedback $\mathrm{L}=$ $\left[\begin{array}{llll}838150000 & 3290000 & 4770\end{array}\right]^{\mathrm{T}}$. Selanjutnya gain tersebut digunakan pada skema pada Gambar 15. Untuk menguji performa estimator maka diberikan kondisi awal pada state $\mathrm{x}_{3}$ tidak sama dengan 0 yaitu sebesar 0,1. Dan didapatkan respon sesuai Gambar 18 .

Gambar 18. Respons sistem work-table CNC dengan kendali estimator berorde penuh

Dan hasil respon dari estimator terhadap nilai awal pada state $\mathrm{x}_{3}=0,1$, diperlihatkan pada Gambar 19.

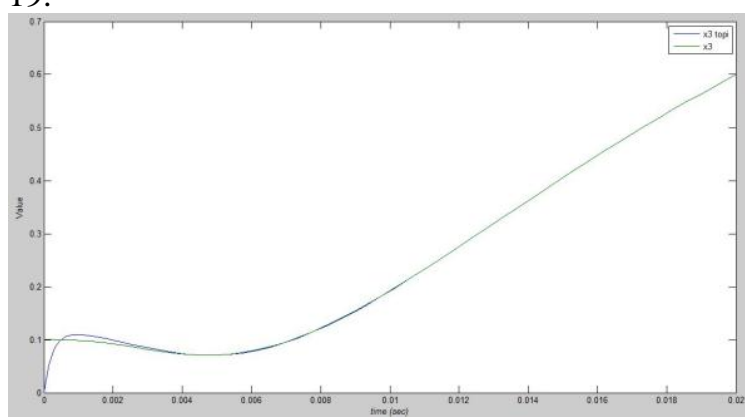

Gambar 19. Respon Estimator berorde penuh terhadap kondisi awal $\mathrm{x}_{3}=0.1$
Dari hasil simulasi didapatkan:

- Maksimal overshoot (\%OS) : 0\%

- $\quad$ Settling Time (Ts) : $0.07 \mathrm{~s}$

- $\quad$ Rise Time (Tr) : 0.0256s

- Kecepatan estimator (Es) : 0,004s

\section{Simulasi Metode Kendali Estimator Berorde Tereduksi}

Pada metode kendali dengan estimator berorde tereduksi yang dirancang, diasumsikan state $\mathrm{x}_{1}$ adalah state yang tidak dapat diukur, sehingga tidak memilikki feedback. Berdasarkan plant sistem pada Gambar 4. dan skema kendali dengan estimator berorde tereduksi pada Gambar 10., dibangun sistem pengendalian yang diperlihatkan pada Gambar 20 .

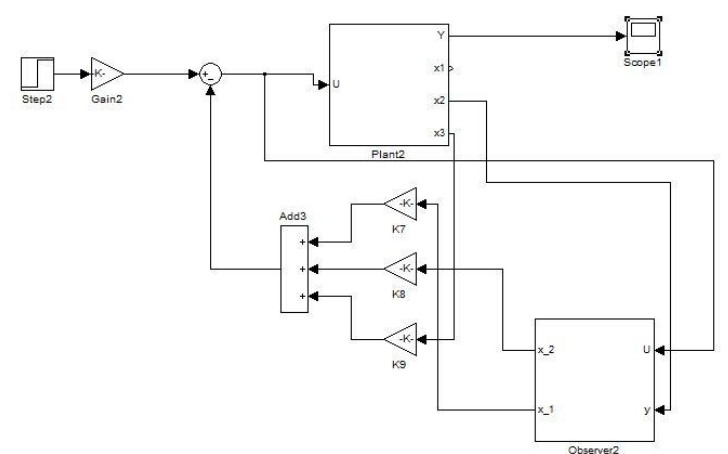

Gambar 20. Respons sistem work-table CNC dengan kendali estimator berorde tereduksi

Model simulink MATLAB untuk estimator berorde penuh diperlihatkan oleh Gambar 21 .

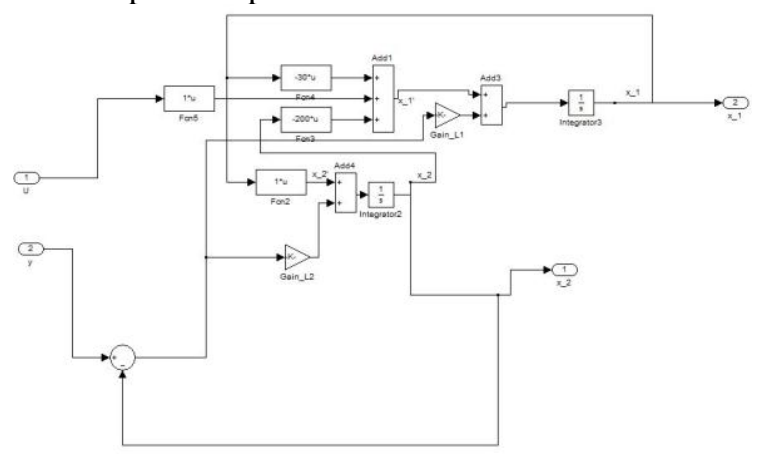

Gambar 21. Skema reduced order estimator

Pada pengontrolan menggunakan estimator berorde penuh perlu ditentukan gain tracking $\mathrm{N}$, gain feedback K, dan gain feedback L pada estimator, untuk pole pada estimator dipilih agar respon estimator lebih cepat 5 kali dari plant sistem, untuk menetukan gain - gain yang diperlukan digunakan perintah MATLAB sebagai berikut

$\%$ state space reduce obs

$\mathrm{F}=[-30-200 ; 10]$

$\mathrm{G}=[1 ; 0]$;

$\mathrm{H}=\left[\begin{array}{ll}0 & 1\end{array}\right]$

$\mathrm{J}=[0]$;

$\%$ find desired poles from specifications

$\%$ Methode: Dominant poles of second-order system $\mathrm{PO}=1 \% \%$ Overshoot 
Ts $=0.05 \%$ Settling time

$\%$ Calculate desired damping ratio (zheta)

$\mathrm{tmp}=\mathrm{pi}^{\wedge} 2+\log (\mathrm{PO} / 100)^{\wedge} 2$

zheta $=-\log (\mathrm{PO} / 100) / \mathrm{sqrt}(\mathrm{tmp})$

$\%$ Calculate desired natural freq

wn $=4 /($ zheta $*$ Ts $)$

$\%$ Desired poles

zhetaWn $=-$ zheta $*$ wn;

wd $=$ wn*sqrt $(1$-zheta*zheta);

$\%$ Desired poles of reduced order system (2nd order dominant poles)

dPoles $1=\left[\right.$ zhetaWn+wd $*$ i zhetaWn-wd $\left.*_{\mathrm{i}}\right]$

$\%$ Full state feedback law...

$\mathrm{K}=$ place $(\mathrm{A}, \mathrm{B}, \mathrm{dPoles})$

$\%$ Reduced-order observer

$\%$ from ref: Linear state space control system

$\%$ desired poles of observer --> $5 \mathrm{x}$

dPoles_obsv $=5 *$ dPoles 1 ;

$\mathrm{L}=\operatorname{place}\left(\mathrm{F}^{\prime}, \mathrm{H}^{\prime}, \mathrm{dPoles} \_\mathrm{obsv}\right)^{\prime}$

Didapatkan nilai gain feedback $\mathrm{K}=[900$ 137200 7502700], gain tracking $\mathrm{N}=$ [7502700] dan untuk gain feedback L = [1033.1 36.7]. Selanjutnya gain tersebut digunakan pada skema pada Gambar 19. Untuk menguji performa estimator maka diberikan kondisi awal pada state $\mathrm{x}_{2}$ tidak sama dengan 0 yaitu sebesar 0,1. Dan didapatkan respon sesuai Gambar 22.

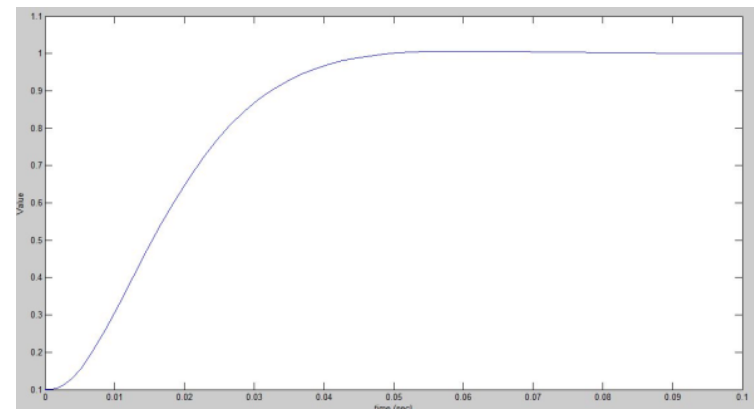

Gambar 22. Respons sistem work-table CNC dengan kendali estimator berorde tereduksi

Dan hasil respon dari estimator terhadap nilai awal pada state $\mathrm{x}_{2}=0,1$, diperlihatkan pada Gambar 23.

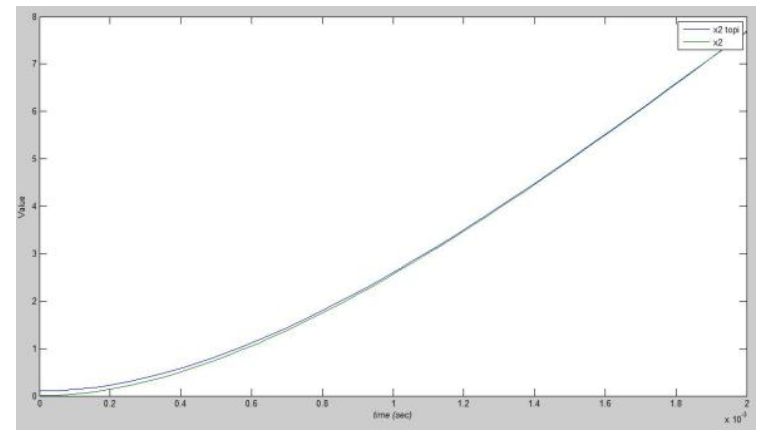

Gambar 23. Respon Estimator berorde tereduksi terhadap kondisi awal $\mathrm{x}_{2}=0.1$

Dari hasil simulasi didapatkan:

- Maksimal overshoot (\%OS) : 0\%
- $\quad$ Settling Time (Ts) : 0.07s

- $\quad$ Rise Time (Tr) : 0.0326s

- Kecepatan estimator (Es) : 0,002s

\section{ANALISIS DAN KESIMPULAN}

Dari hasis simulasi yang dilakukan kita dapat melakukan analisis dari performa masing-masing metode kendali. Hasil simulasi pada metode kendali pole placement menunjukkan performa yang memuaskan untuk kriteria \%OS, sedangkan untuk kriteria Ts belum memenuhi kriteria yang diinginkan, akan tetapi dengan hanya menggunakan metode pole placement sistem tersebut tidak dapat mencapai nilai referensi yang diinginkan, dalam hal ini set point yang diiginkan adalah $=1$. Sistem tersebut hanya mampu mencapai nilai steady sebesar $1.3328 .10^{-7}$ sangat jauh dari nilai set point yang diinginkan. Selanjutnya hasil simulasi metode kendali dengan tracking system menunjukkan performa yang memuaskan untuk kriteria \%OS karena tidak terjadi overshoot, begitu pula untuk kriteria Ts, sistem mampu mencapai kondisi steady di bawah target yang ditentukan. Dan dengan penambahan gain tracking sistem mampu mencapai nilai set point yang diinginkan. Untuk metode kendali state feedback control dengan estimator berorde penuh juga menunjukkan performa yang memuaskan untuk kriteria \%OS karena tidak terjadi overshoot, namun tidak dapat mencapai target settling time yang diinginkan. Dan untuk metode kendali state feedback control dengan estimator berorde tereduksi, hasil simulasi menunjukkan performa yang memuaskan untuk kriteria \%OS karena tidak terjadi overshoot, namun belum mencapai target settling time yang diinginkan.

Secara umum dapat disimpulkan bahwa skema state feedback controller yang digunakan pada penelitian ini dapat digunakan untuk mengendalikan sistem work-table mesin CNC yang dimaksud. Secara natural karakteristik respon transien untuk close loop system pada work-table mesin CNC ini tidak terjadi overshoot, sehingga perbaikkan respon transien terjadi pada kriteria rise time dan settling time yang sangat signifikan hingga mencapai lebih dari 15000 kali lebih baik. Namun untuk kasus non linier, dimana kondisi awal sistem tidak sama dengan 0 , yaitu pada skema kendali kompensator berorde penuh dan kompensator berorde tereduksi, controller belum mencapai spesifikasi kendali yang diinginkan. Untuk kasus pengendalian sistem dengan estimator, estimator berorde tereduksi memilikki performa lebih baik dalam melakukan penjejakan state, implementasi riil dengan estimator berorde tereduksi juga dapat mengurangi beban komputasi karena menurunkan orde dari sistem. Hasil rangkuman dari simulasi yang telah dilakukan pada penelitian ini dapat dilihat pada Tabel 1. 
Tabel 1. Rangkuman Hasil Simulasi

\begin{tabular}{cccccc}
\hline Kriteria & CL & PP & TS & FO & RO \\
\hline$\%$ OS & 0 & 0,71 & 0 & 0 & 0 \\
Ts (s) & 782 & 0,07 & 0,04 & 0,07 & 0,07 \\
Tr (s) & 432 & 0,023 & 0,028 & 0,0256 & 0,033 \\
Es (s) & - & - & - & 0,004 & 0,002
\end{tabular}

Keterangan:

$\mathrm{CL}=$ close loop plant

$\mathrm{PP}=$ pole placement

$\mathrm{TS}=$ tracking system

$\mathrm{FO}=$ kompensator berorde penuh

$\mathrm{RO}=$ kompensator berorde tereduksi

\section{DAFTAR PUSTAKA}

1. Bologa, O., Breaz, R. E., Racz, S. G., \& Crenganiş, M. (2016). Decision-making Tool for Moving from 3-axes to 5-axes CNC Machine-tool. In Procedia Computer Science. https://doi.org/10.1016/j.procs.2016.07.056

2. Dong, X., Jian-qu, Z., \& Feng, W. (2012). Fuzzy PID Control To Feed Servo System of CNC Machine Tool. Procedia Engineering. https://doi.org/10.1016/j.proeng.2012.01.403

3. Dorf, Richard C., and R. H. B. (2011). Modern Control Systems, 12th Edition. Pearson. https://doi.org/10.1109/TSMC.1981.4308749

4. Dorf, R. C., \& Bishop, R. H. (2008). MODERN CONTROL SYSTEMS. System. https://doi.org/10.1109/TSMC.1981.4308749

5. Huang, S., Tan, K. K., Hong, G. S., \& Wong, Y. S. (2007). Cutting force control of milling machine.

Mechatronics. https://doi.org/10.1016/j.mechatronics.2007.07. 005

6. K. Ogata. (2002). Modern Control Engineering. Control Engineering. https://doi.org/10.1109/TAC.1972.1100013

7. Lewis, F. L. (2010). Optimal control. In The Control Systems Handbook: Control System Advanced Methods, Second Edition. https://doi.org/10.1201/b10384

8. Megido, A., \& Ariyanto, E. (2016). SISTEM KONTROL SUHU AIR MENGGUNAKAN PENGENDALI PID. DAN VOLUME AIR PADA TANGKI PEMANAS AIR BERBASIS ARDUINO UNO. GEMA TEKNOLOGI, 18(4), 21-28. Retrieved from https://ejournal.undip.ac.id/index.php/gema_te knologi/article/view/21912

9. Patin Nicolas. (2015). Observers in Control Systems. Control System Design Guide. https://doi.org/10.1016/B978-0122374616/50011-4

10. Tadeus, D. Y., \& Setiono, I. (2018). DESKRIPSI TEKNIS PENGENDALI TEMPERATUR INDUSTRI SEBAGAI BAGIAN DARI SISTEM REGULASI TEMPERATUR. GEMA TEKNOLOGI, 20(1), 1-5. Retrieved from https://ejournal.undip.ac.id/index.php/gema_te knologi/article/view/21075

11. Williams, R. L., \& Lawrence, D. A. (2007). Linear State-Space Control Systems. Linear State-Space Control Systems. https://doi.org/10.1002/9780470117873

12. Gene F. Franklin, J. Da Powell, and Abbas Emami-Naeini. 2014. Feedback Control of Dynamic Systems (7th ed.). Prentice Hall Press, Upper Saddle River, NJ, USA. 